\title{
A215 遠心送風機の特性と舌部近傍の流れ
}

\author{
○小泉 敦司（東海大院），小田切 哲夫（東海大院），青木＼cjkstart克巳（東海大学）
}

\section{The characteristic of a centrifugal blower}

\author{
and the flow near the Tongue
}

\section{Atsushi KOIZUMI and Tetsuo ODAGIRI and Katsumi AOKI}

\section{ABSTRACT}

A study of internal centrifugal blower is very interest in case problems for improve the characteristics. Also, the form of volute tongue which have an affects to characteristics centrifugal blower. This paper is described about effect of tongue shape for characteristics of centrifugal blower. Visualized experiment and numerical calculation for the tongue shape of 3 types clarified the flow characteristic of the flow near the tongue in centrifugal blower. As the results, the following facts are made clear. The behavior of the flow near the tongue agrees with that obsessed by flow visualization experiments. Numbly the stagnation punt moves around the tongue when changing the mass flow.

Key Words: Centrifugal blower, Numerical calculation, Tongue, Flow visualization

\section{1. 緒言}

遠心送風機の舌部近傍の流れに関する研究は, 性能向 上, 不安定現象の改善, 騒音の低减など様々な視点から 行われてきている.しかしながら，これらの問題を克服 するには，ケーシング内部の流れを把握することが重要 である.これまで舌部騒音と性能との関連で種々の研究 が行われてきているが, 舌部形状が変化した時の性能と 内部流れの状態との関連を明らかにしているものは少な い，そこで，本研究ではケーシング構成要素の中で最も 重要と思われる舌部に注目し，舌部形状を変化させ，そ の変化に対する性能特性と各舌部近傍の流れを指向性ピ ト一管による速度分布の測定と, 可視化実験, 並びに数 值解析（RNG k·モモデル）により明らかにしている.

\section{2. 実験装置及び方法}

実験装置の概略を Fig. 1 に示す. 装置は遠心送風機, 電動機部, 流量測定管路部, 火花発生装置, 各測定装置 により構成されている，遠心送風機本体は一般に市販さ れている（ミツヤ送風機 PFC\#21/2）ものを使用し， 可視化実験を行うために透明アクリル板で製作されてい る. 羽根車の概略を Fig. 2 に示す. 羽根車はシュラウド を持つクローズド型羽根車で, 外形 $375 \mathrm{~mm}$, 羽根車数 12 枚, 羽根出口角度 $41^{\circ}$, 羽根曲線に 3 円弧法を用い たものを使用する．実験で用いた 3 種類の舌部形状を Fig.3 に示す.

本実験では，回転数 $2500 \mathrm{rpm}$ 一定のもとで行った. 出口流量はオリフィス流量計より，また軸動力はひずみ 型トルク計より測定した.

また, ケーシング背面部における圧力測定は, 舌部中 央を $0^{\circ}$ とし, $30^{\circ}$ 毎 12 力所に静圧孔をもうけ, スキャ ニーバルブを介してゲッチンゲンマノメータで行った。

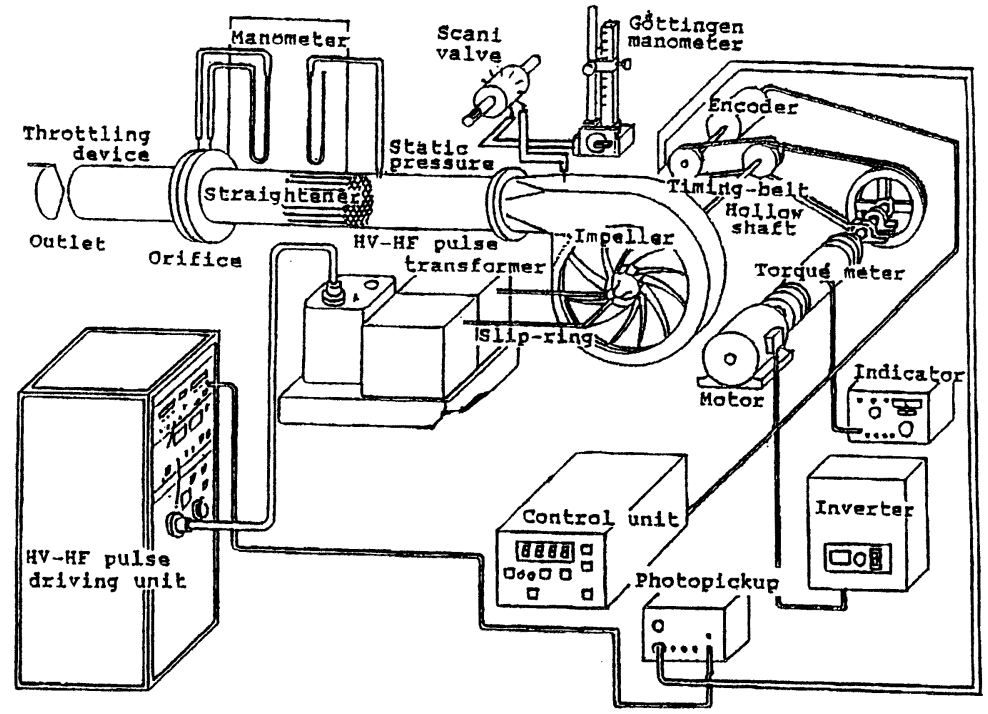

Fig.1 A schematic of experimental

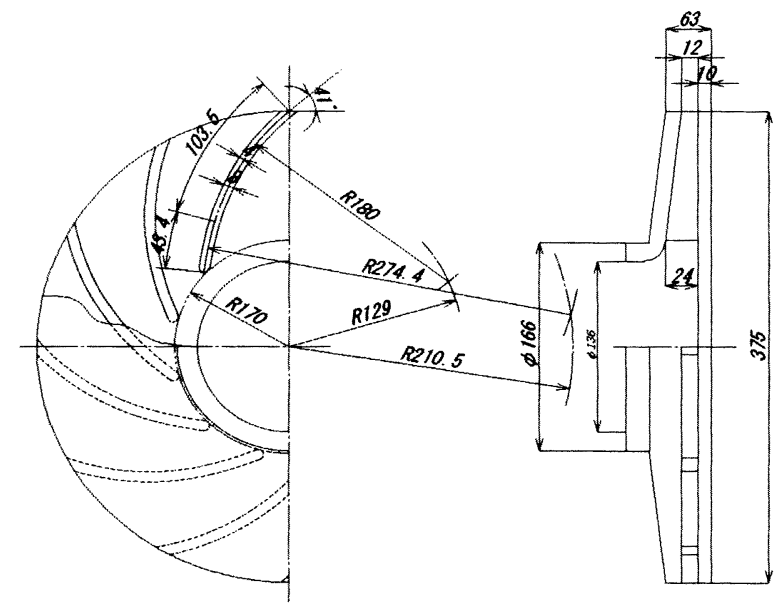

Fig.2 Form of impeller 
可視化には，火花追跡法によって発生させたパルスを 背面側と正面側の 2 方向から撮影した, また火粉法は炭 素粉（カイロ灰）を遠心送風機入口部分より吸い込ませ て撮影した。

\section{4. 実験結果及び考察}

4. 1 性能試験

舌部形状に対する性能試験結果を Fig.4 に示す. その 結果, 最大効率は Type A では $63.1 \%$, Type B では $61.5 \%$, Type C では 58.8\%であった. Type A は他の舌部よりも 圧力係数が高く, 軸動力係数が低い值を示していること により，結果として効率が一番高くなったと思われる. 逆に, Type C に関しては効率の低下が顕著に現れている. これは軸動力倸数がもっとも高い值を示していることが 効率に影響したと考えられる. さらに, Type B, C の結 果を比較する事により舌部先端を上方向に傾斜させると 効率の低下に影響を与えることがわかった.

\section{2 背板面における圧力分布}

次に, 舌部形状に対する背面部の圧力分布結果を Fig.5 に示す. 結果より流量比が小さいほど圧力は全体的に増 大しているのが分かる、ここで，舌部形状が内部流れに 影響すると思われる舌部近傍部分 $\left(\theta=0 \sim 60^{\circ}\right)$ の圧 力分布注目すると, Type A の舌部は流量比を変化させて も圧力分布は直線的に変化しているのに対し, 他の Type の舌部では流量比が大きくなると $\theta$ の角度 $0^{\circ}$ での圧力 が逆に上昇しているのがわかる.この結果より, Type A 以外の舌部では舌部近傍において流れに剥がれが生じ, その現象は流量比が大きくなるに従って顕著に現れてい ると思われる. $\theta>60^{\circ}$ では最高効率点において圧力分 布の差はほとんどない。これより舌部形状の影響は流量 比が小さいほど影響を及ぼすが，最高効率点においては あまり影響を及ぼさないと考えられる。これらの結果よ り Type A が最も速度エネルギーを圧力エネルギーに変 換していることが分かる.

4. 3 舌部近傍の可視化

代表的舌部 Type A において流量比 $\phi / \phi_{\mathrm{n}}$ を $0.2,1.0$ と変化させたとき。火花追跡法をもちいた時の背板面側 と正面側の可視化結果を Fig. 6 に示す.また, 3 孔ピト 一管による速度分布の可視化結果を Fig.7 に示す. 火花追跡法の正面図と速度分布を見て分かるように, 流 量比が小さい場合 $\left(\phi / \phi_{\mathrm{n}}=0.2,0.5\right)$ では主流方向 の流れが舌部入口のスクロール方向に引き込まれている のがわかる.また背板面側からの図を見ると流れに逆流 が生じているのが分かる. 最高効率時（ $\phi / \phi_{\mathrm{n}}=1.0 ）$ では, 低流量時と異なり流れが主流方向に流れており, 背板面側から見た場合も逆流を生じていないのがわかる. 正面から見た流れは, Fig.7の 3 孔ピト一管による速度 分布の結果からもより理解できる.

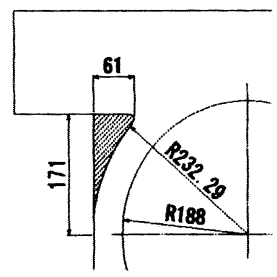

Type A

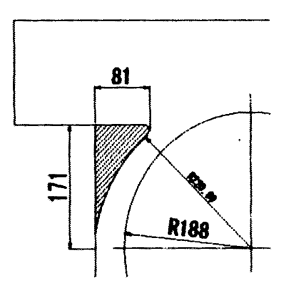

Type B

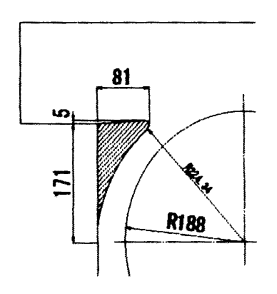

Type C
Fig.3 Tongue type

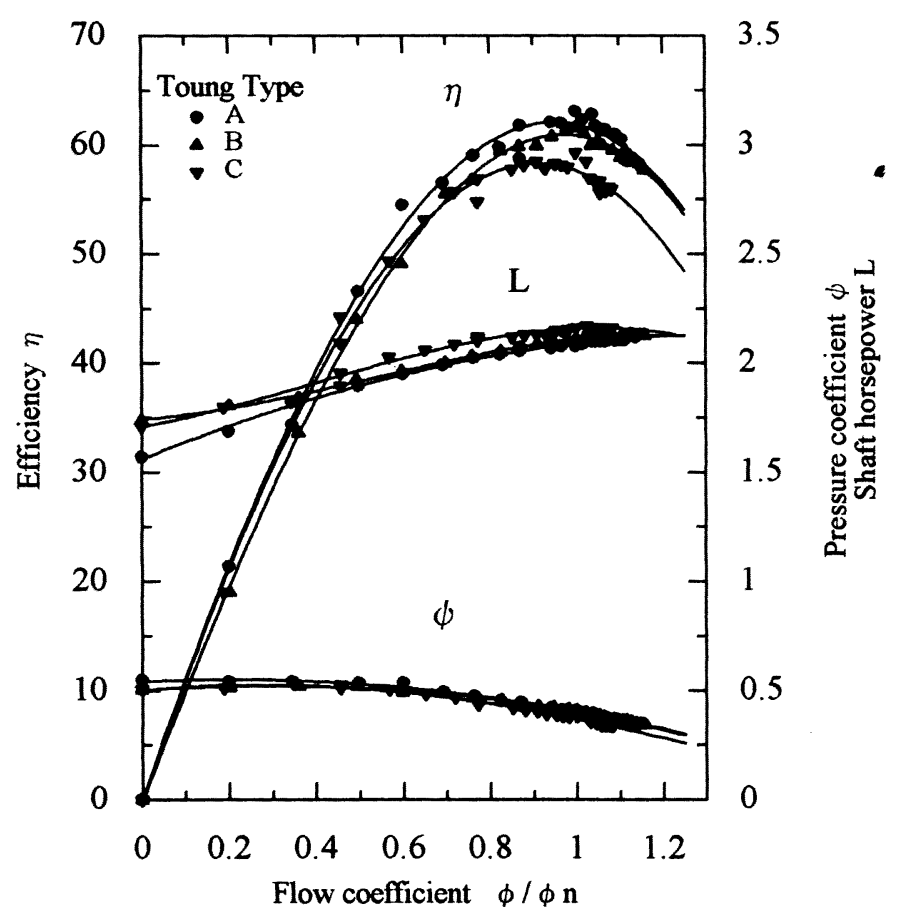

Fig.4 Characterist curve
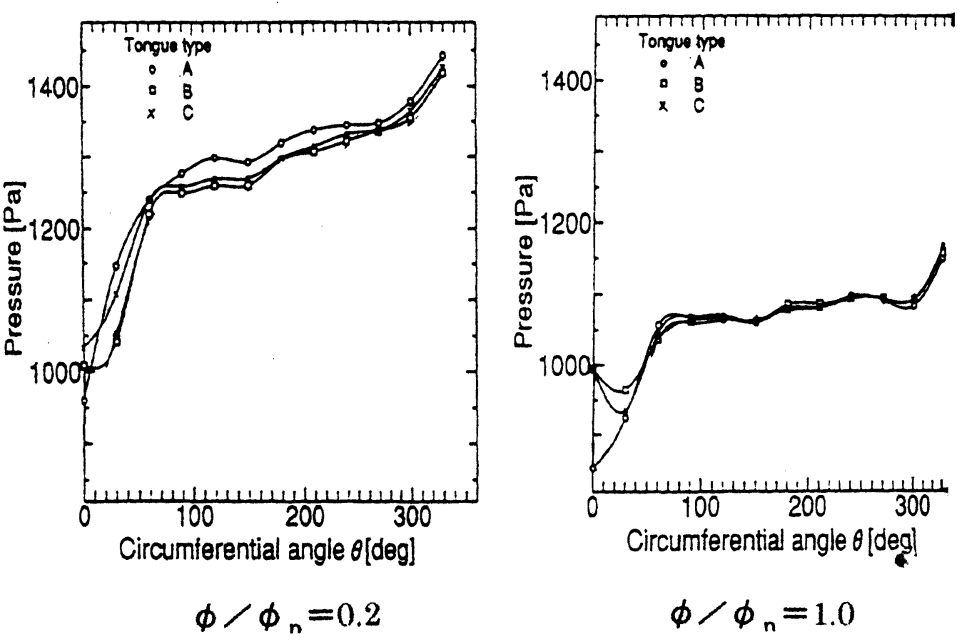

Fig.5 The pressure distribution 

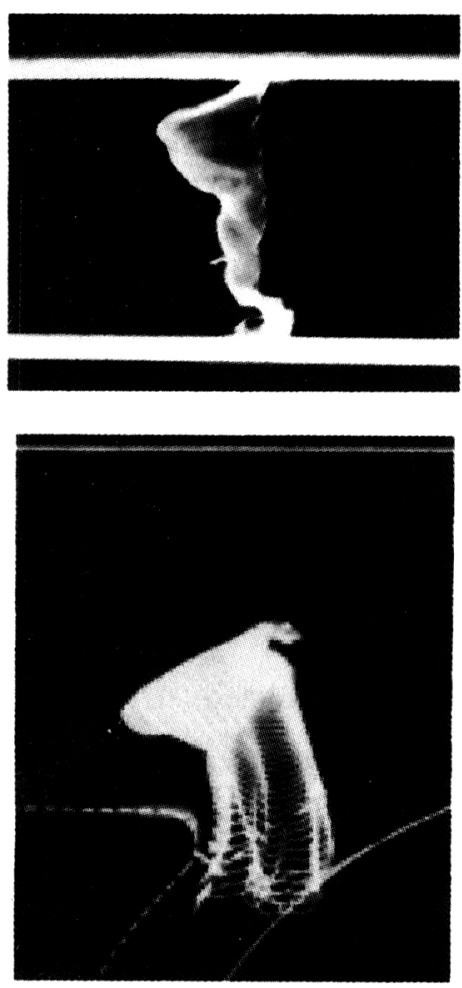

$\phi / \phi_{n}=0.2$
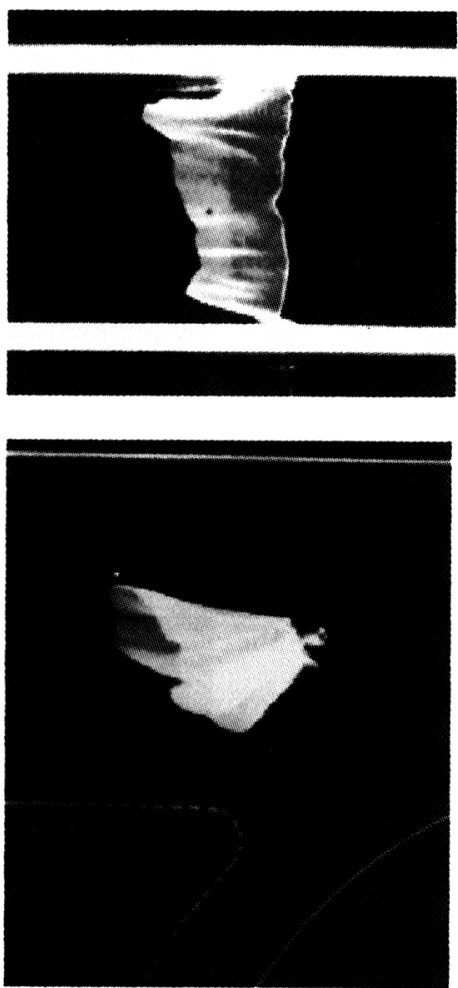

$\phi / \phi_{n}=1.0$

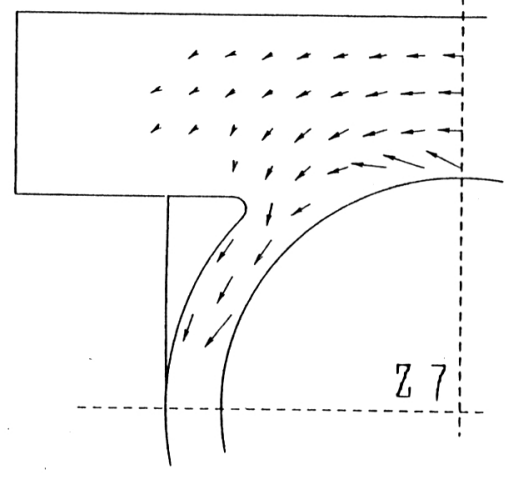

$\phi / \phi_{n}=0.5$

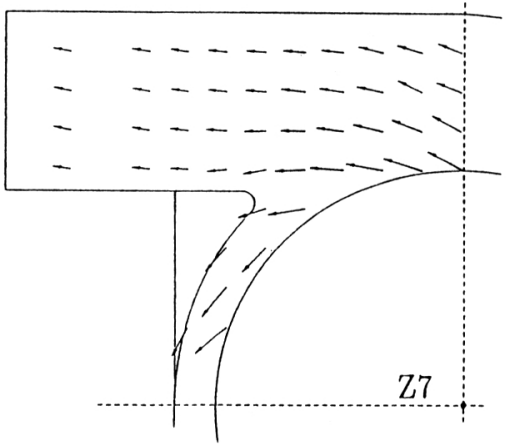

$\phi / \phi_{n}=1.0$

Fig. 7 The velocity vector distribution

Fig.6 Flow visualization by spark tracing method

火粉法と数值解析によって, 各舌部における流量比 $\phi$ $/ \phi_{\mathrm{n}}$ を 0.2, 1.0 と変化させた場合の可視化結果を Fig.8 に示す. 数值解析は, レイノルズ平均したナビエストー クス方程式を有限体積法によって離散化し, 線形化され た方程式系の連立方程式を得るために, SIMPLEアルゴ リズムによって速度場と圧力場を関係付けて反復法によ り解く. 時間積分法はオイラー陰解法を用いる。この数 值計算は Fluent.Inc.の汎用熱流体解析ソフトウエア FLUENT/UNS を用いている.

火粉の可視化結果より，低流量時では, Type A, B, $\mathrm{C}$ ともに舌部上部に流れが鋭角的にぶつかっているのが わかる. 解析結果を見ても流れが舌部上部に衝突し, さ らに, 舌部先端部で出口方向へ流れずにスクロール方 一押し込む流れとなっていることが分かる.これらの結 果から舌部下部で増速をし、圧力が低下していることが 分かる. しかも, 舌部下方の流れは舌部壁面に沿って流 れずに，先端部で剥離をおこし流れ全体が乱れている. さらに Type C は舌部上面が上がっているので, 出口に 向かっていくはずの流れが舌部先端に当たり下方向に押 し流されている. 最高効率時 $\left(\phi / \phi_{n}=1.0\right)$ では, Type $\mathrm{A}, \mathrm{B}$ ともに乱れが少なく, 流線が直線的に現れている. 解析結果を見ても舌部先端によって流れが乱れることな く主流方向とスクロール方向に分割され, 流れが非常に
スムーズに流れているのが分かる.

Type Cにおいては, 舌部近傍の流線が壁面に集中してお り圧力が上がっていると思われる, そのため, 主流方向 流れとの圧力差から出口方向に吸い出されていると考え られる.これは本来最高効率時よりも高い流量比で起こ る逆流現象である，すなわち，舌部形状によっては最高 効率時に最適な流線を描くとは限らないと考えられる.

5. 結言

1) 火花追跡法と 3 孔ピトー管の速度分布結果より流量 比を変化させたときの主流方向とスクロール方向へ の流れの様子を可視化することが出来た.

2) 火粉法と解析結果より流量比を変化させたときの舌 部近傍の詳細な流れの様子が可視化，比較すること が出来た.

3）舌部付近の流れの詳細な現象を見るためには，火花 追跡法, 火粉法などの可視化手法と数值解析解析手 法を比較することが有益である。

4 ) 総合的な判断をすると, 今回使用した舌部の中で Type Aがもっとも高く評価できる. 


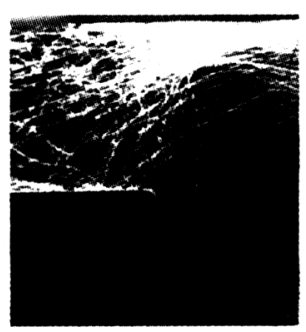

Visualization Type A $\phi / \phi_{n}=0.2$

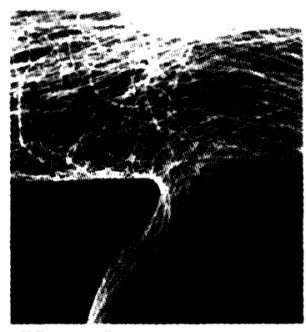

Visualization Type B $\phi / \phi_{n}=0.2$

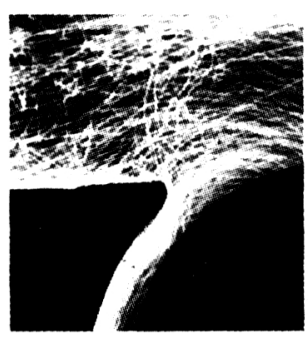

Visualization
Type C

$$
\phi / \phi_{n}=0.2
$$
Calculation

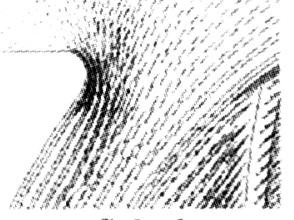

\section{Calculation}

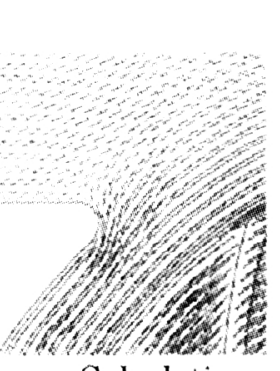

Calculation

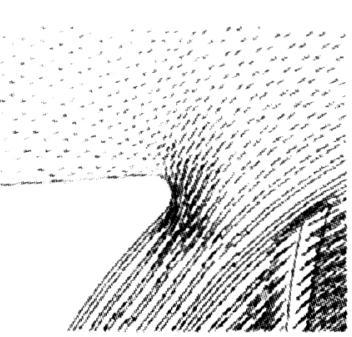

Calculation

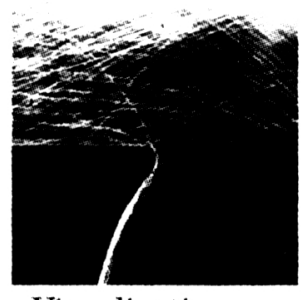

Visualization

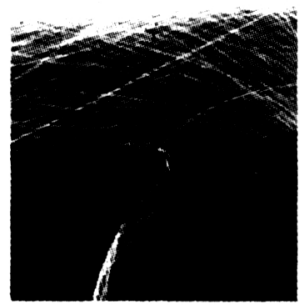

Visualization
Type B

$$
\phi / \phi_{n}=1.0
$$

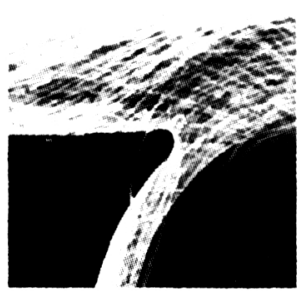

Visualization

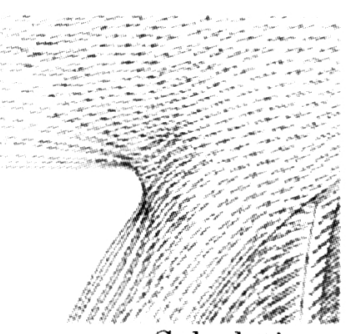

Calculation $\phi / \phi_{n}=1.0$

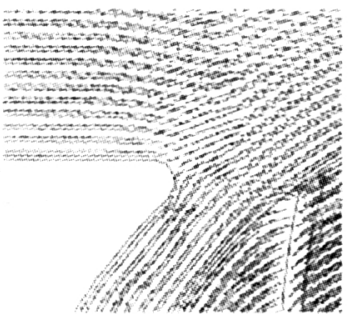

Calculation

Fig.8 Flow visualization carbon ashes

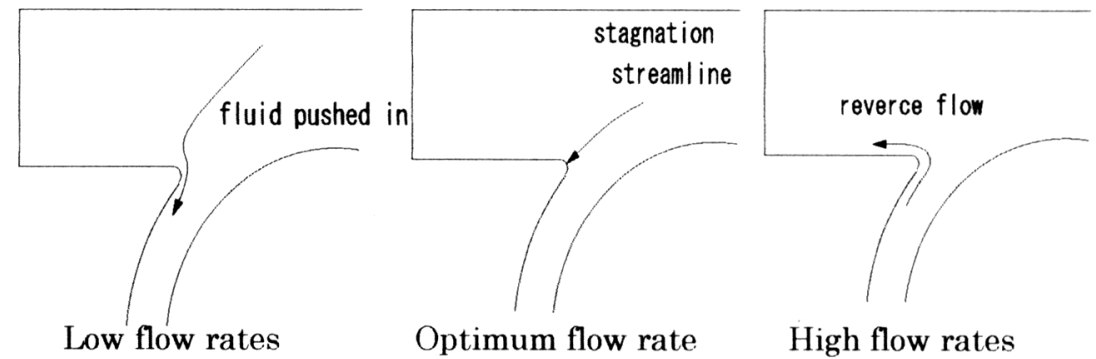

Fig.9 Flow near the tongue

参考文献

（1）村田, 久保, 遠心送風機の変動流れ, 機論, 42 , 353

（2）服部他 3 名, 遠心送風機の低流量機における逆流 現象に関する研究，機論，42，363

(3) 菊山他 2 名, 遠心ポンプ羽根車流露内の圧力変動,

機論, 55,518 